\title{
EVIDENCE FOR A QUASI-PHONON GAP IN CsCl*
}

\author{
C.R. Becker \\ Physikalisches Institut der Universität Freiburg, Germany
}

(Received 18 September 1970 by E. Mollwo)

\begin{abstract}
The observed impurity induced far-infrared absorption in $\mathrm{CsCl}: \mathrm{Rb}^{+}$ and $\mathrm{CsCl}: \mathrm{K}^{+}$is compared with a calculated density of acoustic phonon states in $\mathrm{CsCl}$. The absorption due to $\mathrm{CsCl}: \mathrm{Rb}^{+}$displays a minimum between the acoustic and optic phonon bands. A narrow line is observed in $\mathrm{CsCl}: \mathrm{K}^{+}$at $85.8 \mathrm{~cm}^{-1}$ which falls in this quasi-phonon gap.
\end{abstract}

A GAP BETWEEN the acoustic and optic phonon bands in $\mathrm{CsCl}$ has been predicted by Mahler ${ }^{1}$ utilizing Schröder's 'breathing shell' model. ${ }^{2}$ The present far-infrared measurements are an attempt to show if such a gap exists or not. More recently, an extension of Mahler's calculation by $\mathrm{Jex}^{3}$ to over $1.7 \times 10^{5}$ points in the Brillouin zone, predicts a small, but nevertheless finite, density of phonon states between the acoustic and optic branches.

As has been known for some time, $\mathrm{CsCl}$ undergoes a phase transition ${ }^{4}$ [ $\mathrm{CsCl}$ (b.c.c.)

$\mathrm{CsCl}$ (f.c.c.)] at $469^{\circ} \mathrm{C}$ which makes it difficult to grow single crystals of $\mathrm{CsCl}$. However, by using platinum as a seed crystal and slowly cooling the resultant crystals, single crystals of $\mathrm{CsCl}$ were grown from the melt in an argon atmosphere using the Kyropoulos method. In addition, one crystal was grown in air. The concentration of $\mathrm{K}^{+}$in the doped crystals was determined by flame spectroscopy ${ }^{5}$ whereas a similar determination of $\mathrm{Rb}^{+}$was not possible due to the close proximity of $\mathrm{Rb}^{+}$and $\mathrm{Cs}^{+}$lines. The far infrared measurements were made on crystals at $4.9-5.1^{\circ} \mathrm{K}$ using a RIIC Fourier spectrometer employing a Golay cell as a detector.

* This research was supported by the Deutsche Forschungsgemeinschaft.
Mahler's gap and Jex's minimum occur at approximately $87-97 \mathrm{~cm}^{-1}$ and $79-98 \mathrm{~cm}^{-1}$ at $4.2^{\circ} \mathrm{K}$ respectively. Experimentally, a minimum in the additional absorption induced by $\mathrm{Rb}^{+}$was observed at the somewhat lower frequency range of $76-88 \mathrm{~cm}^{-1}$ as shown in Fig. 1. However, at

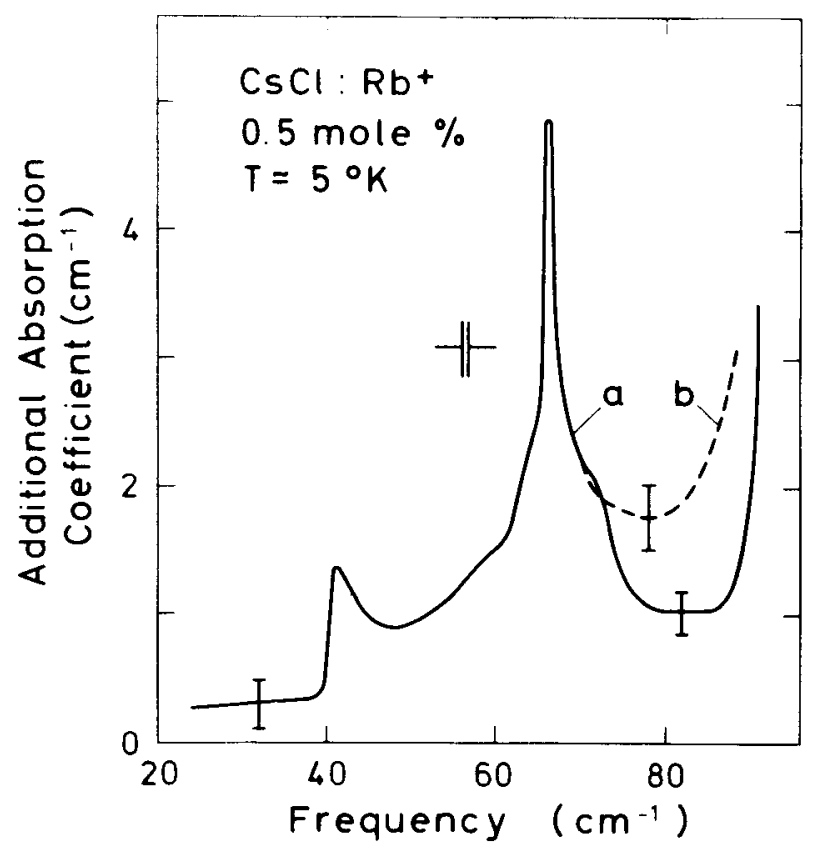

FIG. 1. Impurity induced absorption in $\mathrm{CsCl}: \mathrm{Rb}^{+}$; (a) grown in an argon atmosphere and (b) grown in air. The given mole per cent of $\mathrm{Rb}^{+}$is the concentration in the melt. 
frequencies approaching $88 \mathrm{~cm}^{-1}$ a good assignment was not possible due to the strong absorption of the hot crystal itself. Hence, $88 \mathrm{~cm}^{-1}$ is merely a lower limit for the high frequency edge. This minimum, with respect to other features in the spectrum, was found to be shallower for a similarly doped crystal which was grown in air instead of argon and which therefore contains, among other things, large quantities of $\mathrm{OH}^{-}$. This may be explained by a preferential increase in activation of one-phonon processes which results from the translational symmetry perturbation of the additional impurities.

A narrow line in $\mathrm{CsCl}: \mathrm{K}^{+}$was observed at $85.8 \mathrm{~cm}^{-1}$ which falls within the minimum mentioned above; see Fig. 2. This line has a

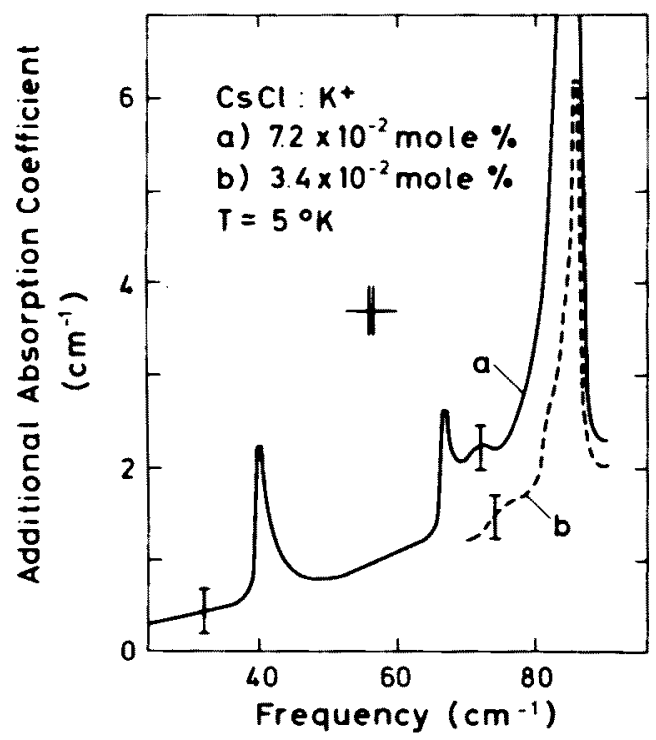

FIG. 2. Impurity induced absorption in $\mathrm{CsCl}: \mathrm{K}^{+}$. The $\mathrm{K}^{+}$concentrations were determined photometrically.

width at half-maximum of about $1 \mathrm{~cm}^{-1}$ which would be smaller if it were not for a low frequency shoulder due, in all probability, to a heavier isotope, ${ }^{41} \mathrm{~K}$, whose natural abundance is 6.91 per cent. The narrowness of this line is a good argument for a small, if not zero, density of phonon states within this minimum. Thus, subject to future slow neutron scattering experiments, we tentatively assign the absorption in this minimum to one-phonon processes and the minimum itself to a quasi-phonon gap.

Two maxima occur at 41.1 and $66.2 \mathrm{~cm}^{-1}$ in $\mathrm{CsCl}: \mathrm{Rb}^{+}$. The latter is relatively narrow with a width at half-maximum of $\leqslant 2 \mathrm{~cm}^{-1}$, while the former is somewhat broader due to a shoulder on the high frequency side. Moreover, two similar maxima occur in $\mathrm{CsCl}: \mathrm{K}^{+}$at 40.1 and $67.0 \mathrm{~cm}^{-1}$. In this case the former is more symmetrical and therefore narrower. It seems reasonable that the two maxima in both $\mathrm{CsCl}: \mathrm{Rb}^{+}$and $\mathrm{CsCl}: \mathrm{K}^{+}$are due to the same two critical points in the Brillouin zone because the differences in frequency are smaller than those which may accompany the activation of phonons. ${ }^{6}$ Furthermore, using the assumption that the impurity ions occupy a $\mathrm{Cs}^{+}$ lattice site, these two critical points are assigned to $X_{5}^{\prime}$ and $R_{15}$ by means of Mahler's calculation shown schematically in Fig. 3.

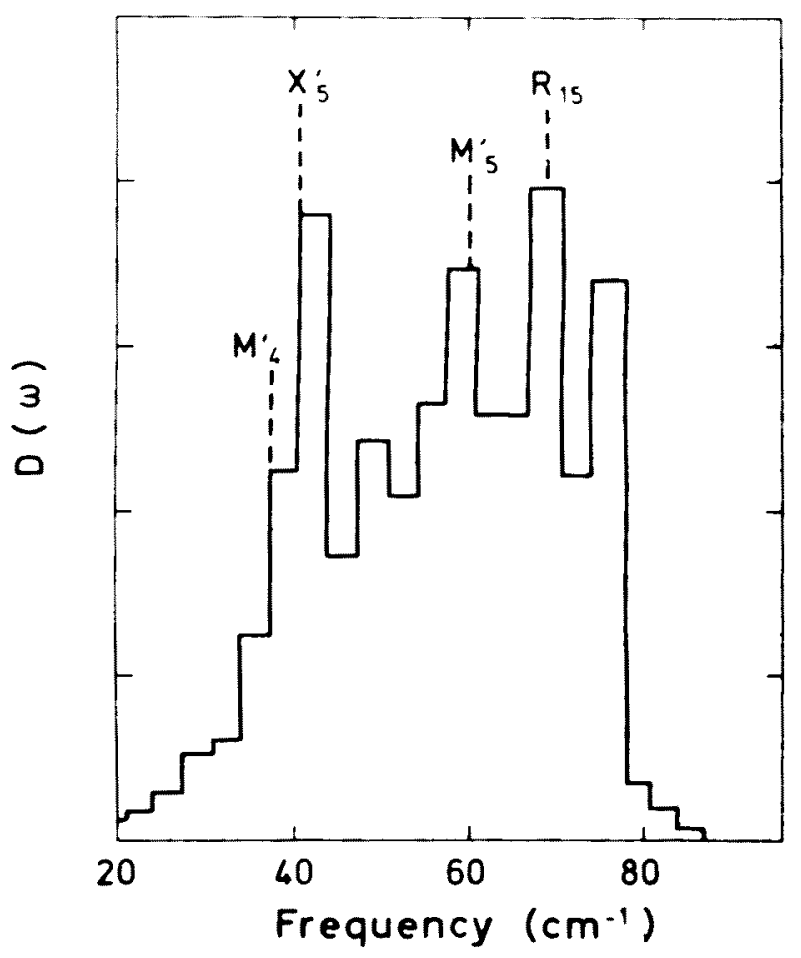

Fig. 3. The calculated density of phonon states, $D(\omega)$, at $4.2^{\circ} \mathrm{K}$ according to Mahler.

An observed minimum in the additional absorption of $\mathrm{CsCl}: \mathrm{Rb}^{+}$has been tentatively 
assigned to a quasi-phonon gap. Within this quasi-phonon gap, $\mathrm{CsCl}: \mathrm{K}^{+}$produced a narrow line at $85.8 \mathrm{~cm}^{-1}$ reminiscent of a localized gap mode.* Two maxima in the spectra have been assigned to two critical points, $X_{5}^{\prime}$ and $R_{15}$, in the Brillouin zone.

* If the density of phonon states is not zero, this is really a resonant mode.
Acknowledgements - The author acknowledges helpful discussions with Prof. Dr. L. Genzel, Dr. T.P. Martin and Dr. W. Prettl. In addition we would like to thank Dipl.-Phys. M. Schuhmacher who grew the crystals, as well as G. Mahler and Dr. $\mathrm{H}$. Jex who were kind enough to make available their unpublished calculations. Gratitude is also extended to the Deutsche Forschungsgemeinschaft which provided a financial grant for this work.

\section{REFERENCES}

1. MAHLER G., Diplomarbeit, Phys. Institut, Frankfurt.

2. SCHRÖDER U., Solid State Commun. 4, 347 (1966).

3. JEX H., Private communication.

4. MENARY' J.W., UBBelohde A.R. and WOODWARd I., Proc. R. Soc. (London) A208, 158 (1951).

5. .DEAN J.A., Flame Photometry p. 167. McGraw-Hill, New York (1960).

6. SZIGETTI W., J. Phys. Chem. Solids 24, 225 (1963).

Defektinduzierte Fern-Infrarot Absorption in $\mathrm{CsCl}: \mathrm{Rb}^{+}$und $\mathrm{CsCl}: \mathrm{K}^{+}$ wird mit einer berechneten Zustandsdichte der akustischen Phononen verglichen. Die Absorption von $\mathrm{CsCl}: \mathrm{Rb}^{+}$zeigt ein Minimum zwischen den akustischen und optischen Phononenzweigen. In $\mathrm{CsCl}: \mathrm{K}^{+}$wird eine schmale Linie bei $85,8 \mathrm{~cm}^{-1}$ beobachtet, die in das quasi-phonongap fällt. 